\title{
Do Individual Differences in Sociosexuality Represent Genetic or Environmentally Contingent Strategies? Evidence From the Australian Twin Registry
}

\author{
J. Michael Bailey \\ Northwestern University
}

Michael P. Dunne

Queensland University of Technology
Katherine M. Kirk and Gu Zhu

Queensland Institute of Medical Research and University of Queensland

\author{
Nicholas G. Martin \\ Queensland Institute of Medical Research and \\ University of Queensland
}

\begin{abstract}
Although men are substantially more interested than women in casual sex, there is ample variation in this trait (sociosexuality) within both sexes. One theory hypothesizes that within-sex sociosexual variation results from genetic variation maintained by frequency-dependent selection. If so, sociosexuality should be substantially heritable. A competing theory is that children acquire their mating strategy after observing their parents' relationship. By this theory, sociosexuality should reveal a strong shared environmental component. The authors studied genetic and environmental influences on sociosexuality using a large, representative volunteer twin sample. Parental marital instability was modestly associated with sociosexuality, but this could have been due to either genetic or environmental factors. Consistent with genetic theory, familial resemblance appeared primarily due to additive genetic rather than shared environmental factors.
\end{abstract}

On average, men are more willing than women to engage in casual sex. This sex difference is large by conventional standards, nearly one standard deviation (Oliver \& Hyde, 1993). In recent years, the predominant theory offered to explain this fact has been evolutionary (Buss, 1994; Symons, 1979; Trivers, 1972; Wright, 1994). Parental investment theory (Trivers, 1972) emphasizes the sex difference in the minimum investment parents make in their children. Because the sexes differ enormously in both their minimum reproductive investment and their maximum reproductive output, men have had more to gain and less to lose, evolutionarily, by having sex with someone outside the confines of a committed relationship. In principle, a man could generate an extra descen-

J. Michael Bailey, Department of Psychology, Northwestern University; Katherine M. Kirk, Gu Zhu, and Nicholas G. Martin, Epidemiology Unit, Queensland Institute of Medical Research, Brisbane, Queensland, Australia, and Joint Genetics Program, University of Queensland, Brisbane, Queensland, Australia; and Michael P. Dunne, School of Public Health, Queensland University of Technology, Brisbane, Queensland, Australia.

This research was supported by Grant MH47227 from the National Institute of Mental Health and by a Commonwealth AIDS Research Grant (Australia). We thank John Pearson for data management and Olivia Zheng, Ann Eldridge, Sue Mason, and Theresa Pangan for their work in administering the questionnaire. We thank Martie Haselton and Joan Linsenmeier for comments on an earlier version of the article. Most of all, we thank the twins for their cooperation.

Correspondence concerning this article should be addressed to J. Michael Bailey, Department of Psychology, Northwestern University, 2029 Sheridan Road, Evanston, Illinois 60208-2710. Electronic mail may be sent to jm-bailey@nwu.edu. dant for little more than the cost of the time to copulate. Even a man with a partner could have greatly increase his reproductive success by copulating with other women, if the cost was low. In contrast, a woman must minimally invest 9 months of pregnancy and, typically, many years of childrearing (for she is there when the child is born) in order to reproduce successfully. Men are unusual among male primates in the high degree of investment they typically make in their children and partners (Diamond, 1998). A single woman who had casual sex risked getting pregnant before insuring such investment. Furthermore, a woman with a fertile partner was unlikely to add to her expected reproductive output through a casual dalliance. Instead, she risked losing her partner's investment.

An important empirical challenge to this evolutionary account is the fact that there is both substantial within-sex variation and substantial overlap between the sexes in the propensity to engage in casual sex (sociosexuality; Simpson \& Gangestad, 1991). If casual sex opportunities have been so favorable for men, why do some men refuse them? If casual sex has been so detrimental to women's reproductive success, why do some women accept, or even seek out, such opportunities?

Two main evolutionary theories have attempted to explain sociosexual variation within the sexes. One theory stresses genetic and biological environmental factors (Gangestad \& Simpson, 1990; Gangestad \& Thornhill, 1997), and the other, social environmental factors (Belsky, Steinberg, \& Draper, 1991), in causing sociosexual differences among people. Both theories hypothesize that much of the variation is organized and strategic. That is, according to the theories, sociosexual variation exists because 
optimal mating strategies depended on circumstances that varied among individuals or across time.

According to genetic theory, men differ in their genetic quality. (This variation is maintained partly by a slow, steady stream of mostly deleterious mutations and partly by the dynamics of parasite resistance; see Cronin, 1991; Gangestad \& Thornhill, 1997.) Men with favorable genotypes are better able to resist infection and other developmental stresses, and women may prefer them as sex partners for several reasons. First, such men provide better genes to the women's offspring. Second, the men may be healthier and thus better able to invest in their partners and offspring. Third, the men may be less likely to harbor parasites and infect their partners and offspring. Because women should prefer men with favorable genotypes, such men may offer less investment and emotional commitment in exchange for sexual opportunities. These men should be especially likely to develop an unrestricted sociosexual orientation (i.e., have a high interest in casual sex). In contrast, men with less favorable genotypes should have fewer mating opportunities, and thus must offer more commitment to a potential mate. They should thus be more likely to develop a restricted sociosexual orientation (i.e., have less interest in casual sex).

The genetic theory hypothesizes that female sociosexual variation reflects women's "decisions" regarding how much commitment to trade for genetic quality. Women who value commitment much more than male quality have a restricted sociosexual orientation, and women with opposite preferences have an unrestricted orientation. This variation has been hypothesized to be maintained by frequency-dependent selection (Gangestad \& Simpson, 1990). That is, the success of genes favoring either a restricted or an unrestricted strategy is greatest when they are uncommon, and as a result, neither strategy completely replaces the other.

To date, two main findings have supported genetic theory. First, men with low levels of fluctuating asymmetry (FA) have sex earlier, with more partners, and with less investment compared with other men (Cronin, 1991; Gangestad \& Thornhill, 1997). Low FA is a marker of developmental stability, which is a marker of "good genes" (Gangestad \& Thornhill, 1997). Second, when evaluating potential mates, women with an unrestricted orientation tend to emphasize traits likely to reflect genetic quality, including attractiveness and dominance, more than do other women (Mikach \& Bailey, 1999; Simpson \& Gangestad, 1992).

In contrast, social theory (Belsky et al., 1991) hypothesizes that early family environments signal the kind of mating system that children are likely to face as adults, and thus they adjust their mating physiology and psychology accordingly. (The theory has focused primarily on female sociosexuality and sexual development, but analogous predictions appear to follow for males.) Specifically, according to social theory, girls whose fathers have abandoned the family, or whose parents' relationship is conflictual, "infer" that paternal investment (in their own eventual offspring) is unlikely. As a result, their development is altered in several ways: They mature earlier, adopt a suspicious attitude toward men, and become more sociosexually unrestricted. Evidence for social theory includes the surprising finding that aspects of parental relationships such as father absence and family conflict are correlated with daughters' earlier menarche (Moffitt, Caspi, Belsky, \& Silva, 1992; Steinberg, 1988). There has been less attention to the covariation between sociosexuality and either family stress or pubertal onset. In one study, women with many sex partners did not differ from other women in their age of menarche (Mikach \& Bailey, 1999).

\section{Behavioral Genetics and Sociosexual Variation}

Genetic and social theories generate quite different expectations concerning the genetic architecture of sociosexuality. First, consider social theory. Several rather strong assumptions are necessary for female sociosexual variation to have evolved in the way that social theory hypothesizes. First, in ancestral environments, frequent shifts must have occurred between high and low paternal investment mating systems (respectively, "Dads" and "Cads" [Wilson, 1994]). Such shifts would be necessary for the evolution of such a complex, contingent adaptation. Second, although frequent shifts must have occurred within populations over time, in general, fathers' behavior must have been a reliable indicator of paternal investment at daughter's age of reproduction; crossgenerational changes in mating system would disrupt fatherdaughter signaling. Third, within ancestral breeding populations, men would have needed to be rather homogenous in their sexual strategies (nearly all "Dads" or all "Cads"). Otherwise, there would be little benefit to a daughter drawing inferences about the likelihood of paternal investment from her father's behavior.

By social theory, the predominant determinant of female sociosexual variation should be the environment shared by siblings reared together (shared environment). If a father's behavior has been a reliable signal of the mating environment to one child, then it should also have been a reliable signal to the others. Social theory would have difficulty accounting for either substantial genetic variation or nonshared environmental variation in sociosexuality.

In contrast, genetic theory requires that sociosexual variation be at least partially heritable (Buss and Greiling, 1999). According to this theory, heritable variation in genetic quality drives male sociosexual variation, and heritable variation in strategic tradeoffs, subject to frequency-dependent selection, drives female sociosexual variation. Furthermore, unrestricted women should seek unrestricted men (because the latter have good genes), thus insuring a genetic correlation between male and female sociosexuality. Thus, genetic theory predicts heritability for sociosexuality in both sexes as well as a positive correlation between opposite sex relatives' sociosexuality.

Unlike social theory, genetic theory would have little difficulty accounting for nonshared environmental influences. This is because the proximate signal of genetic quality is developmental stability (of which one indicator is FA), and developmental stability is affected by both genetic and environmental factors. Behavior geneticists have, in fact, speculated that nonshared environmental variance is often attributable to biological factors that idiosyncratically affect developmental stability (Molenaar, Boomsma, \& Dolan, 1993). Consistent with the importance of nonshared environment for developmental stability, one study recently showed a strong correlation between monozygotic (MZ) twin differences in facial asymmetry and differences in facial attractiveness (Mealey, Bridgstock, \& Townsend, 1999). MZ twin differences are due to the nonshared environment, and differences in facial attractiveness are plausibly related to developmental stability. Genetic theory also allows shared environmental effects, if factors that affect 
developmental stability vary between families. In contrast to social theory, however, genetic theory does not require such effects.

To date, no behavioral genetic study has focused on sociosexuality per se, although there have been at least three studies that are indirectly relevant. Martin and Eysenck (1976) studied "libido," which included items highly relevant to sociosexuality (e.g., "Sex is more exciting with a stranger"). They concluded that libido was primarily genetic in males and primarily environmental in females. However, their sample sizes (ranging from 93 for female $M Z$ pairs to only 17 for male dizygotic [DZ] pairs) were far too small to find reliable differences. In a relatively small sample of twins, Gangestad and Simpson (1993) found significant and substantial heritability of a latent personality trait which, they argued, is genetically related to sociosexuality. This support for their theory was limited in several respects, however. First, and most obviously, they did not examine sociosexuality directly. Second, they did not examine men and women separately, and thus it was unclear whether their scale was heritable in both sexes. Furthermore, their sample contained only same-sex twins, and thus, the familial correlation between male and female sociosexuality could not be examined. A third study examined genetic and environmental influences on romantic "lovestyles," and found that in contrast to most other traits that have undergone behavioral genetics analyses, these appeared to be strongly influenced by the shared environment (Waller \& Shaver, 1994). However, although the pattern of twin correlations was consistent with a shared environmental interpretation, the shared environmental parameter estimates were not statistically significant. Thus, available behavioral genetics studies on sociosexuality have provided conflicting and indefinite evidence.

\section{The Present Study}

We administered a scale of sociosexuality to 4,901 Australian twins, comprising 1,890 male, female, and opposite-sex pairs as well as 1,121 twins whose co-twins did not participate. Because our measure was new, we examined its construct validity by replicating the sex difference and exploring its associations with several relevant self-reported sexual behaviors.

Social theory predicts that parental marital instability should be related to one's sociosexuality. Thus, we examined whether participants whose parents were unmarried, divorced, or separated had more unrestricted sociosexual orientation.

The primary goal of the present study was to examine the genetic architecture of sociosexuality. Specifically, social theory predicts that sociosexual variation should primarily reflect shared environmental influences. In contrast, genetic theory requires some heritable variation in sociosexuality but also allows nonshared and shared environmental influences.

\section{Method}

\section{Participants}

Participants were drawn from the Australian National Health and Medical Research Council Twin Register (ATR). The ATR is a volunteer registry begun in 1978 and has about 25,000 twin pairs of all zygosity types and all ages enrolled and in various stages of active contact. (For more details of the sample, see Bailey, Dunne, \& Martin, 2000; Dunne et al., 1997.)
During 1992 we asked all ATR twins between ages 18 and 50 years and who had completed a postal health and lifestyle survey (HLQ) between 1988 and $1990(N=9,112)$ about their willingness to receive a questionnaire regarding sex. All those who said "Yes" were mailed the sex questionnaire. When participants received the sex questionnaire, they were asked to complete a consent form with their name, date of birth, and signature, and to return this separately to indicate whether or not they had consented to complete the sex questionnaire. Anonymity was assured. Approximately 2 weeks after initial mailing of the sex questionnaire, all twins were sent a reminder letter.

Twenty-eight percent of those approached explicitly refused to participate, and $54 \%(4,901)$ completed questionnaires. The remainder $(18 \%)$ initially agreed to participate but did not respond when contacted (following one letter or one phone call). Our response rate was not substantially lower than that of other recent large-scale mail sex surveys, which have typically achieved responses rates between 55 and 65\% (Biggar \& Melbye, 1992; Johnson et al., 1989; Sundet, Magnus, Kvalem, Samuelsen, \& Bakketeig, 1992).

Participants' ages ranged from 19 to 51, with a mean of 31 years for both men and women ( $S D=8$ years). Half the women were currently married, compared with $42 \%$ of the men.

\section{Measures}

Zygosity. Zygosity of twins was established at the time of their completing the HLQ, from their response to standard items about physical similarity and being mistaken for each other. Such items have been shown by ourselves and by others to be at least $95 \%$ accurate when judged against genotyping results (e.g., Kasriel \& Eaves, 1976; Martin \& Martin, 1975). We further improved on this by selecting for further investigation any pair whose answers were not completely consistent, within or between cotwins, with either mono- or dizygosity. These pairs were telephoned to detect the source of any confusion, and about $80 \%$ were readily decided on the phone. Those still equivocal were asked to send us photographs at several stages of their lives and most were then assigned with little hesitation by the project staff, leaving but a few genuinely doubtful cases. Where possible, blood was subsequently obtained for genotyping these few uncertain pairs. We recently genotyped 329 same-sex pairs whose zygosity had been assigned using the above procedures, with 11 independent highly polymorphic markers. Of 131 pairs who reported themselves to be DZ, 5 (3.8\%; 4 female, 1 male) were concordant at all loci, with a probability of monozygosity of over .9999 . Of the 198 pairs who reported themselves to be MZ, none was found to be DZ. The accuracy overall was $98.5 \%$ (Duffy, 1994).

Sociosexuality Scale (SS). The primary measure used in this study consisted of 20 items, included in the Appendix. Seven of the items were adapted from Simpson and Gangestad's (1991) Sociosexuality Orientation Inventory. An additional 13 items were taken from Eysenck's (1976) study of the genetics of sexual behavior. The latter were selected on the basis of face validity. Fifteen of the items were in "yes" or "no" response format, and the remaining 5 used an 8-point rating scale. Each item was standardized over the entire sample, and then the 20 items were summed to form the total score of the dependent variable, SS. Missing items were assigned a value equal to the mean of the participant's nonmissing items, and a maximum of 6 missing items was allowed for each individual before the scale score was set to missing. Higher scores on our scale represent a more unrestricted sociosexual orientation.

Separate scree tests for men and women confirmed the importance of only one factor accounting for shared item variance. The full scale correlated highly with the items adapted from the Sociosexuality Orientation Inventory (.89 for both men and women), but its reliabilities were higher (coefficient $\alpha$ of .88 for men and .85 for women, vs. .74 and .70, respectively). For both men and women, the item with the highest item-total correlation was "It would be difficult for me to enjoy having sex with someone I did not know very well" (scored false). 
Sexual history variables. In order to examine the construct validity of our sociosexuality measure, we assessed several variables concerning relevant sexual history. These included, for example, whether respondents had ever had sex with someone they had met the same day or whether they had ever had a sexually transmitted disease. These variables were not part of the sociosexuality measure.

Demographic variables. The following variables were assessed: sex, age, social class (working, middle, or upper class, with lower, middle, or upper gradation; thus, a 9-point scale was used), marital status (currently married vs. divorced, separated, or never married), and parent's marital status. Regarding the last variable, we considered parents' marriages to be stable if they were currently married or widowed, and unstable if they were divorced, separated, or had never married. Fourteen percent of men and $18 \%$ of women reported that their parents' marriages had been unstable, by our definition.

\section{Data Analysis}

Sociosexuality as an ordinal variable. It is well known that the distribution of a scale depends primarily on the characteristics of its items including their difficulty and response type (i.e., dichotomous or ratingscale) (Lord \& Novick, 1968; Nunnally \& Bernstein, 1994). Thus, the distribution of a scale does not reveal the intrinsic distribution of a trait.

Because some of our analyses, and especially our behavior genetic analyses, are sensitive to distributional assumptions, we have made the following a priori assumptions, which are both highly plausible and increasingly used in similar studies (Lyons et al., 1997). First, we considered SS to be an ordinal, rather than an interval, scale. Second, we assumed that the true underlying trait distribution was normal. This assumption is plausible if there are at least several causes of trait variation, each of which has a modest effect on the population (Falconer, 1989; Gottesman \& Carey, 1983; Reich, Cloninger, \& Guze, 1975). If so, according to the Central Limit Theorem, the trait will be approximately normal.

The most important data analytic consequence of the ordinal assumption concerns the appropriate index of correlation. Strictly speaking, the Pearson correlation requires interval-level measurement and is thus inappropriate for ordinal analyses. Instead, we used the polychoric correlation, which is the correlation between ordinal variables. Thus, for example, the correlation between parental marital status and participant's SS score assumed that both variables were measured ordinally, and thus, that parental marital status also depended on an underlying normal distribution (in this case, the liability to marital instability).

In order to compute polychoric correlations, the SS was first transformed into a 10-point ordinal scale. Because men and women had such different distributions, this transformation was done within sex, with approximately equal numbers of male or female participants with each score. The polychoric correlation is computed from the full contingency table crossclassifying two ordinal variables using the PRELIS program (Jöreskog \& Sörbom, 1993). Confidence intervals of polychoric correlations (and parameter estimates derived from them) may be asymmetric under some circumstances, and thus we provide confidence intervals rather than standard errors.

Regression analyses. In order to investigate the association between parental marital status and SS scores, we performed simultaneous multiple regression analyses. Covariates included several variables that might plausibly be related to SS, including participant's age, marital status, and social class. Because co-twins are nonindependent observations (and hence can inflate Type I errors), we adopted the following approach. First, we divided the entire sample into two subsamples, by splitting each complete twin pair randomly and then by assigning singletons randomly to one or the other subsample. Next, each simultaneous multiple regression analysis was performed separately on each subsample. Because each subsample was so large $(N \mathrm{~s}=2,319$ and 2,327), and thus had substantial statistical power, we elected to take a conservative approach with respect to statistical significance. In order to be considered significant, a parameter would have to be significant $(p<.05)$ in both subsamples. We report the higher probability estimate from the two subsamples but report parameter estimates and proportions of variance from analyses performed on the total sample.

Genetic and environmental model fitting. We fitted two genetic and environmental structural models by maximum likelihood estimation using the MX program (Neale, 1995). These models used as their input the polychoric correlations and associated asymptotic covariance matrices for both same-sex pairs and opposite-sex pairs. First, a full model was fitted to men and women. Using the model, we examined the relative effects of additive genetic (A), shared environmental (C; i.e., between family or common environment), and nonshared environmental ( $E$; i.e., within family or individual-specific environment, including measurement error) factors on the latent normal variable underlying variation in SS scores. In the full model, we allowed separate parameter estimates for both sexes. We also examined the possibility that different genes affect male and female sociosexuality (i.e., sex limitation), by allowing the opposite-sex DZ pairs to have a genetic correlation of less than .5 (Neale, 1995). Finally, we included age as a parameter, to control for age-related variation in SS scores.

In the second, reduced model, we did not allow sex limitation, and we constrained parameter estimates to be equal across the sexes. Because the second model is a nested subset of the first model, we tested whether its fit was significantly worse using a likelihood ratio chi-square test. A rough guide to a model's fit and parsimony is provided by the Akaike Information Criterion (AIC; $\chi^{2}-2 d f ;$ Akaike, 1983). Models with negative AIC values are preferred.

\section{Results}

Raw SS scores (obtained by summing the standardized items) were available for 1,794 men and 3,029 women. The mean for men $(M=6.7)$ significantly exceeded that for women $(M=-3.9)$, $t(4821)=35.2, p<.001$. The effect size for the sex difference $(d=1.0)$ was large by conventional standards (Cohen, 1987). The male variance $\left(S^{2}=146.2\right)$ also significantly exceeded the female variance $\left(S^{2}=76.7\right), F(1793,3028)=1.9, p<.001$.

In order to examine the construct validity of our sociosexuality measure, we compared the highest and lowest quintiles on the measure, separately for men and women, on several relevant sexual history items. These results are presented in Table 1 . There

Table 1

Comparison of Top and Bottom Quintiles on Self-Reported Behavioral Correlates of the Sociosexuality Scale Scores (in Percentages)

\begin{tabular}{|c|c|c|c|c|}
\hline \multirow[b]{2}{*}{ Item } & \multicolumn{2}{|c|}{ Women } & \multicolumn{2}{|c|}{ Men } \\
\hline & Top & Bottom & Top & Bottom \\
\hline $\begin{array}{l}\text { Had sex with someone the same day } \\
\text { you met }\end{array}$ & 59 & 6 & 78 & 12 \\
\hline $\begin{array}{l}\text { Got pregnant, or got someone } \\
\text { pregnant, before marriage }\end{array}$ & 32 & 9 & 31 & 8 \\
\hline Had sex after having a lot to drink & 77 & 25 & 88 & 34 \\
\hline Was unfaithful to a steady partner & 48 & 3 & 63 & 5 \\
\hline $\begin{array}{l}\text { Had sex with two people in a } 24 \text { hour } \\
\text { period }\end{array}$ & 29 & 1 & 50 & 2 \\
\hline Ever had a sexually transmitted disease & 19 & 4 & 24 & 4 \\
\hline
\end{tabular}

Note. All differences were significant $(p<.001)$ even with conservative corrections for statistical non-independence (i.e., dividing the sample size in half). 
Table 2

Simultaneous Regression of Sociosexuality Scale Scores on Parental Marital Status and Covariates

\begin{tabular}{lll}
\hline \multicolumn{1}{c}{ Variable } & $R^{2}$ & $\Delta R^{2}$ \\
\hline Parental marital status & $.002^{*}$ & $.001^{*}$ \\
Age & $.006^{*}$ & $.003^{*}$ \\
Marital status & $.032^{*}$ & $.035^{*}$ \\
Social class & .002 & .003 \\
\hline
\end{tabular}

Note. $N=4,547 . \Delta R^{2}$ is the incremental contribution of each variable. ${ }^{*} p<.05$ in both random subsamples.

were marked, highly significant differences between high and low scorers, for both men and women.

Table 2 gives the results of our regression analyses of SS on parental marital stability, controlling for age, marital status, and social class. Parameter estimates did not differ significantly by sex, and thus Table 2 reports results for the combined sample. Significant predictors included marital status, age, and parental marital status. Participants whose parents had had unstable marriages had higher SS scores, as did currently unmarried participants and older participants. The social class measure did not meet our significance criteria (although it was significant in one subsample), but its coefficient indicated that higher social class participants had higher SS scores.

\section{Testing Methodological Assumptions}

Ascertainment bias. Because our twin sample (like most twin samples) consists of volunteers, it is conceivable that self-selection or ascertainment bias may affect results. For example, if twins who were most similar to each other tend to volunteer more readily, this would inflate correlations. This would be particularly worrisome if such bias occurred more (or less) often among MZ than among DZ twins. Examination of means and variances in complete versus incomplete pairs provides one means of investigating whether a twin sample suffers from ascertainment biases (Neale \& Eaves, 1993). Neither raw means nor variances in SS scores differed significantly by zygosity for either men or women. For women, SS scores among twins in complete pairs did not differ significantly from twins whose co-twins did not participate $(p>90)$. For men, however, twins in incomplete pairs obtained significantly higher scores than those in complete pairs, $t(1785)=3.7, p<.001$. This difference was primarily due to unpaired $\mathrm{DZ}$ twins, whose average score was approximately one fourth of a standard deviation higher than the other twins. This suggests that there was some ascertainment bias among male DZ twins, although it is difficult to know how such bias affected genetic and environmental parameter estimates without knowing the scores of the missing twins.

Equal environment assumption. A fundamental assumption of the classical twin method that we have adopted is that the traitrelevant environments are no more similar for $\mathrm{MZ}$ than for $\mathrm{DZ}$ twins. There are some environmental respects in which $\mathrm{MZ}$ twins are typically more similar than DZ twins (e.g., they are more likely to have been dressed similarly as children), but it is an empirical question as to whether these are trait-relevant respects. If they are, then similarity for the putative environmental influences should predict trait similarity. We used four standard items of similar childhood experiences (whether twins shared the same room, had the same playmates, were dressed alike, and were in the same classes at school). For same-sex twin pairs we summed the items to create an index of similarity in childhood experiences. Coefficient alpha for the composite ranged between .63 for male $\mathrm{DZ}$ twins to .69 for female $\mathrm{MZ}$ twins. Correlations between co-twins' composites ranged from .49 for male DZ twins to .66 for female $\mathrm{MZ}$ twins, suggesting that the twins' memories were fairly reliable. Thus, we summed co-twins composites to form an overall index of similar childhood experiences, and used it in a subsequent analysis to determine whether similar childhood experiences could explain similarity in same-sex co-twins' SS scores.

In order to examine the equal environments assumption, we correlated absolute intrapair differences in SS with the Equal Environments composite, our measure of how similarly twins were treated in childhood, separately for male MZ, male DZ, female $\mathrm{MZ}$, and female $\mathrm{DZ}$ pairs. The first three correlations (respectively, .01, -.11 , and -.02 ) were small and nonsignificant $(p>$ .10). Although the correlation for $D Z$ female pairs was significant, it was trivial in magnitude, $r(357)=-.12, p<.05$, accounting for less than $2 \%$ of the variance in intrapair differences. Thus, the equal environments assumption did not appear to have been seriously violated.

\section{Genetic and Environmental Influences on Sociosexuality}

Table 3 contains the polychoric correlations to which genetic and environmental models were fitted. The MZ correlations were higher than $\mathrm{DZ}$ correlations, consistent with a genetic effect. The opposite-sex DZ correlation significantly exceeded zero, suggesting that some similar familial influences affect both male and female sociosexuality. On the other hand, the fact that this correlation was lower than the harmonic mean of the same-sex DZ correlations was consistent with some sex-limitation (Cloninger, Christiansen, Reich, \& Gottesman, 1978).

Table 4 gives parameter estimates for the full model with sex limitation and sex-specific parameters, as well as for the reduced model with no sex limitation and equal parameter estimates for both sexes. Both models could be rejected on formal grounds because their associated chi-square values were significant. However, with sufficient sample size, any interesting model will be rejected because all scientific models are approximations, and hence have error (Browne \& Cudeck, 1993). The more important issue of statistical inference, then, concerns whether a given model's particular components are statistically necessary. For the full model, the estimates for male heritability (.26) and shared environmentality $(.24)$ were similar, but neither was significant. For

Table 3

Polychoric Correlations and Confidence Intervals

\begin{tabular}{lccc}
\hline Zygosity group & $\begin{array}{c}N \\
\text { pairs }\end{array}$ & $\begin{array}{c}\text { Polychoric } \\
\text { correlation }\end{array}$ & $\begin{array}{c}95 \% \text { confidence } \\
\text { interval }\end{array}$ \\
\hline Male MZ & 304 & .52 & $.42-.56$ \\
Male DZ & 179 & .35 & $.21-.48$ \\
Female MZ & 650 & .55 & $.49-.60$ \\
Female DZ & 364 & .32 & $.23-.42$ \\
Opposite-sex DZ & 346 & .16 & $.05-.27$ \\
\hline
\end{tabular}


Table 4

Parameter Estimates (and 95\% Confidence Intervals) for the Full and Reduced Models

\begin{tabular}{|c|c|c|c|}
\hline \multirow[b]{2}{*}{ Parameter } & \multicolumn{2}{|c|}{ Model $1^{\mathrm{a}}$} & \multirow{2}{*}{$\frac{\text { Model } 2^{\mathrm{b}}}{\begin{array}{c}\text { Men and } \\
\text { women }\end{array}}$} \\
\hline & Men & Women & \\
\hline \multicolumn{4}{|l|}{$A^{2}$} \\
\hline Estimate & 0.26 & 0.43 & 0.49 \\
\hline \multicolumn{4}{|l|}{$C^{2}$} \\
\hline Estimate & 0.24 & 0.09 & 0.02 \\
\hline $\mathrm{E}^{2}$ Confidence interval & $.00-.50$ & $.00-.31$ & $.00-.16$ \\
\hline Estimate & 0.49 & 0.46 & 0.47 \\
\hline Confidence interval & $.37-.60$ & $.38-.54$ & $.40-.53$ \\
\hline \multicolumn{4}{|l|}{$\operatorname{Age}^{c}$} \\
\hline Estimate & 0.02 & 0.02 & 0.02 \\
\hline Confidence interval & $.00-.04$ & $.01-.04$ & $.01-.03$ \\
\hline $\mathrm{r}_{\mathrm{A}, \mathrm{D} \mathbf{z}}^{\mathrm{b}}$ & \multicolumn{2}{|c|}{0.04} & $\begin{array}{c}0.50 \\
\text { fixed parameter }\end{array}$ \\
\hline$x^{2}$ & \multicolumn{2}{|c|}{$\begin{array}{c}0.00-1.00 \\
14.3\end{array}$} & 21.5 \\
\hline$d f$ & \multicolumn{2}{|c|}{7} & 11 \\
\hline$N$ & \multicolumn{2}{|c|}{1497} & 1497 \\
\hline$P$ & \multicolumn{2}{|c|}{0.046} & 0.029 \\
\hline Akaike's Information Criterion & \multicolumn{2}{|c|}{.3} & -0.5 \\
\hline
\end{tabular}

Note. $\mathrm{A}=$ additive genetic; $\mathrm{C}=$ shared environmental; $\mathrm{E}=$ nonshared environmental.

${ }^{a}$ Model 1 had sex limitations and sex-specific parameters. ${ }^{\text {b }}$ Model 2 did not have sex limitations and had the same parameters for men and women. ' Proportion of variance accounted for by age. ${ }^{d}$ Sex limitation parameter, which represents the correlation of additive genetic deviations for opposite-sex dizygotic (DZ) twins. The parameter is fixed to 0.50 if no sex limitation is assumed.

women, heritability was the much larger estimate ( .43 vs. .09 ), and it was significant. For both men and women, nonshared environment accounted for an appreciable proportion of variance (.49 and 46 , respectively) and was significant.

The fit of the more parsimonious reduced model was not significantly worse than that of the full model, $\chi^{2}(4$, $N=1,497)=7.2, p>.7$. By the reduced model, which constrained parameter estimates to be equal across the sexes, heritability (.49) was substantial and significant, and shared environmentality (.02) was small and nonsignificant. As with the full model, nonshared environmentality $(.47)$ remained large. Thus, the simplest interpretation of the data (as evidenced by the reduced model's low AIC) is that genetic influences are the sole cause of familial aggregation in sociosexuality, that the same genes operate in males and females, and that they account for $49 \%$ of the variation in both sexes.

\section{Discussion}

Sociosexuality was associated with large differences in selfreported sexual behavior, for both men and women. Considering the nature and magnitude of its correlates, sociosexuality would seem potentially important to consider in studies of such phenomena as marriage and divorce, unintended pregnancy, infidelity, and sexually transmitted diseases. There has recently been a surge of interest in the possibility that humans engage in sperm competition (Baker \& Bellis, 1993). Our finding that sociosexuality is strongly related to a history of "double matings," or a woman's having sex with two men during a short enough time period that she could be simultaneously inseminated by both, suggests that researchers interested in sperm competition should include sociosexuality as a potential moderator variable.

Women in the top female quintile of the SS were nearly as elevated in their relevant sexual experiences as men in the top male quintile, even though the 80th female percentile was equivalent to only the 39th male percentile. This provides further support for the idea, considered elsewhere (Bailey, Gaulin, Agyei, \& Gladue, 1994; Symons, 1979), that female sexuality constrains male sexuality. That is, given a woman and a man with similar inclinations to casual sex, the woman will realize her ambitions more readily than will the man.

The causes and correlates of individual differences in sociosexuality appear to be similar in men and women. Demographic variables did not interact with sex in the prediction of sociosexuality, suggesting that similar relations held for both sexes. Genetic and environmental model fitting did not reveal significant sex differences in either the nature or magnitude of genetic or environmental influences on sociosexuality, although there was some indication of sex limitation. Specifically, the opposite-sex DZ correlation was about half the same-sex DZ correlations. The test for sex-limitation in the classical twin study is not very powerful (Prescott \& Gottesman, 1993), and thus it is possible that an even larger, statistically more powerful study would have revealed a significant sex difference in causal architecture.

\section{Social Versus Genetic Theory}

Our results bear directly on the competition between social and genetic explanations of sociosexual variation. Although our results cannot exclude the possibility of social influences on sociosexuality, they are difficult to reconcile with the particular social theory espoused by Belsky et al. (1991). First, the mere existence of substantial variation in sociosexuality, as evidenced by the differences in sexual histories of the top and bottom quintiles, is a problem for social theory. If our ancestral cultures were so variable in sociosexual behavior, with a large subset of men likely to be unreliable mates and a large subset likely to be reliable, then what purpose would it serve a daughter to draw inferences about the culture from her father's behavior? It is possible that ancestral cultures were less variable in sociosexuality than the Australian sample was, but the theory of Belsky et al. (1991) provides no explanation of why variance should have increased.

Consistent with social theory, we found an association between parental marital instability and sociosexuality. However, the magnitude of the association $\left(\Delta R^{2}=.001\right)$ was trivial. We note that this analysis was not an optimal test of social theory because parental marital stability was measured cumulatively at the time of our survey and not at the theoretically critical period of childhood. Thus, for example, a parental marriage that was happy until a participant was 30 years old would have been counted as unstable provided that the participant indicated that the parents had divorced.

Most relevant, then, were our genetic and environmental analyses. Parameter estimates for shared environment, which social theory predicts should be preeminent, were nonsignificant and, with one exception (for males in the full model), relatively small. This was true despite the fact that assortative mating for a trait inflates shared environmental estimates (Neale \& Cardon, 1992), 
and there is evidence that people mate assortatively with respect to sociosexuality (Simpson \& Gangestad, 1992): In contrast, and in accordance with genetic theory, heritability estimates were moderate and, with one exception (again for males in the full model), significant. Furthermore, as we have noted, genetic theory is better able than is social theory to explain the substantial nonshared environmental influences we found.

One potential limitation of our findings concerns nonadditive genetic factors, such as dominance. We assumed that nonadditive genetic factors were nonexistent because the twin method cannot detect them well. Whenever both nonadditive genetic and shared environmental influences are important, the twin method will underestimate the importance of shared environmental influences and overestimate the influence of additive genetic factors (Grayson, 1989). In order to control for this possibility, it would be desirable to study the correlation in sociosexuality between half siblings, or between parents and offspring, whose genetic resemblance reflects additive genetic factors but not dominance.

Our results increase the prior odds that genetic theory is correct and decrease the prior odds that social theory is correct, although they do not conclusively resolve the issue. Both theories may be wrong, for example. One clear consequence of our study, however, is that researchers should be careful in drawing environmental conclusions from correlational studies of parental and offspring mating behavior. Thus, for example, our finding that parental marital instability is modestly associated with participants' sociosexuality is easily interpretable as a genetic effect. Parents with unrestricted patterns of sociosexuality are both more likely to be in impermanent marriages and to transmit relevant genes to their children, causing elevated SS scores in the latter. Thus, for example, approximately half of the men and women in the top (withinsex) quintiles of sociosexuality had been sexually unfaithful to a steady partner; this was more than a tenfold increase over the corresponding rate for people in the bottom quintiles. Sexual infidelity is a common cause of divorce cross-culturally (Buss, 1994). Thus, given the apparent strong additive genetic influence on sociosexuality, which causes increased resemblance between parents and offspring, it seems most likely that the correlation between parental marital status and offspring sociosexuality is primarily due to genetic factors. This interpretation is also consistent with the finding that divorce is moderately heritable (McGue \& Lykken, 1992). In contrast with our reasoning, two recent studies finding similar associations interpreted them environmentally (Barber, 1998; Waynforth, Hurtado, \& Hill, 1998). Our study provides scant support for such interpretations.

Social theory has been supported primarily by studies linking menarche with aspects of the parental (Belsky et al., 1991), or of the father-daughter (Ellis, McFadyen-Ketchum, Dodge, Pettit, \& Bates, 1999), relationship. Although our results argue against the broad theory espoused by Belsky et al. (1991), a different evolutionary hypothesis might explain the association between menarche and an unfavorable parental or father-daughter relationship (see, e.g., Ellis \& Dahl, 1999). If, for example, fathers signal their intention not to invest in particular daughters by means of aspects of the father-daughter relationship, then it could be adaptive for daughters whose fathers will not invest to begin reproducing earlier rather than waiting for paternal investment that will not come. (A poor parental relationship is also plausibly predictive of low paternal investment.) This differs from the social theory outlined by Belsky et al. (1991) because by the new hypothesis girls are inferring the likelihood of paternal investment in themselves, rather than the general likelihood of paternal investment within a culture. The new hypothesis is more easily reconciled with nonshared environmental influences. It remains to be specified, however, what circumstances should lead a father not to invest in a particular daughter.

\section{Within-Versus Between-Sex Variation}

The focus of this study was on the origins of sociosexuality differences within the sexes. In principle, the origins of sex differences can be completely different than the origins of within-sex differences, and at the genetic level this must be so. The sexes differ only in their sex chromosomes, and there is no reason to think that genes for sociosexuality are more likely to be on the sex chromosomes than on the autosomes.

Our study may not be entirely irrelevant to the origins of the sex difference, however. In sexual selection-and in particular, in the case of sociosexuality - the optimum for a trait frequently differs between men and women. In such cases, alleles that benefit men are harmful to women and vice versa. This situation has been called "sexually antagonistic selection" (Rice, 1999). This impedes the fixation of relevant alleles (because, for example, an allele may be favored when in a male body and disfavored when in a female body), maintaining heritable variation in the trait. This assumes that relevant alleles have similar phenotypic effects in men and women. Thus, our findings of heritability for male and female sociosexuality, as well as the fact that male and female sociosexuality were correlated, provide some indirect support for the evolutionary explanation of the sex difference in sociosexuality. At the same time, one must be cautious in drawing inferences about the origins of sex differences from data on differences within the sexes.

\section{References}

Akaike, H. (1983). Information measures and model selection. Bulletin of the International Statistical Institute, 50, 277-290.

Bailey, J. M., Dunne, M. P., \& Martin, N. G. (2000). Genetic and environmental influences on sexual orientation and its correlates in an Australian twin sample. Journal of Personality and Social Psychology, 78, 524-536.

Bailey, J. M., Gaulin, S., Agyei, Y., \& Gladue, B. A. (1994). Effects of gender and sexual orientation on evolutionarily relevant aspects of human mating psychology. Journal of Personality and Social Psychology, 66, 1081-1093.

Baker, R. R., \& Bellis, M. A. (1993). Human sperm competition: Ejaculate manipulation by females and a function for the female orgasm. Animal Behaviour, 46, 887-909.

Barber, N. (1998). Sex differences in disposition towards kin, security of adult attachment, and sociosexuality as a function of parental divorce. Evolution and Human Behavior, 19, 125-132.

Belsky, J., Steinberg, L., \& Draper, P. (1991). Childhood experience, interpersonal development, and reproductive strategy: An evolutionary theory of socialization. Child Development, 62, 647-670.

Biggar, R. J., \& Melbye, M. (1992). Responses to anonymous questionnaires concerning sexual behavior: A method to examine potential biases. American Journal of Public Health, 82, 1506-1512.

Browne, M. W., \& Cudeck, R. (1993). Alternative ways of assessing model fit. In K. A. Bollen \& J. S. Long (Eds.), Testing structural equation models (pp. 136-162). Thousand Oaks, CA: Sage.

Buss, D. M. (1994). The evolution of desire: Strategies of human mating. New York: Basic Books. 
Buss, D. M., \& Greiling, H. (1999). Adaptive individual differences. Journal of Personality, 67, 209-243.

Cloninger, C. R., Christiansen, K. O., Reich, T., \& Gottesman, I. I. (1978). Implications of sex differences in the prevalences of antisocial personality, alcoholism, and criminality for familial transmission. Archives of General Psychiatry, 35, 941-951.

Cohen, J. (1987). Statistical power analysis for the behavioral sciences (Rev. ed.). Hillsdale, NJ: Erlbaum.

Cronin, H. (1991). The ant and the peacock: Altruism and sexual selection from Darwin to today. New York: Cambridge University Press.

Diamond, J. (1998). Why is sex fun?: The evolution of human sexuality. New York: Basic Books.

Duffy, D. L. (1994). Asthma and allergic diseases in Australian twins and their families. Unpublished doctoral dissertation, University of Queensland, Brisbane, Queensland, Australia.

Dunne, M. P., Martin, N. G., Bailey, J. M., Heath, A. C., Bucholz, K. K., Madden, P. A. F., \& Statham, D. J. (1997). Participation bias in a sexuality survey: Psychological and behavioural characteristics of responders and non-responders. International Journal of Epidemiology, 26, 844-854.

Ellis, B. J., \& Dahl, R. (1999). Timing of pubertal maturation in girls: A life history approach. Unpublished manuscript, University of Canterbury, Christchurch, New Zealand.

Ellis, B. J., McFadyen-Ketchum, S., Dodge, K. A., Pettit, G. S., \& Bates, J. E. (1999). Quality of early family relationships and individual differences in the timing of pubertal maturation in girls: A longitudinal test of an evolutionary model. Journal of Personality and Social Psychology, 77, 387-401.

Eysenck, H. J. (1976). Sex and personality. Austin: University of Texas Press.

Falconer, D. S. (1989). Introduction to quantitative genetics (3rd ed.). New York: Longman.

Gangestad, S. W., \& Simpson, J. A. (1990). Toward an evolutionary history of female sociosexual variation. Journal of Personality, 58, 69-96.

Gangestad, S. W., \& Simpson, J. A. (1993). Development of a scale measuring genetic variation related to expressive control. Journal of Personality, 61, 133-158.

Gangestad, S. W., \& Thornhill, R. (1997). Human sexual selection and developmental stability. In J. A. Simpson \& D. T. Kenrick (Eds.), Evolutionary social psychology (pp. 169-196). Mahwah, NJ: Erlbaum.

Gottesman, I. I., \& Carey, G. (1983). Extracting meaning and direction from twin data. Psychiatric Developments, 1, 35-50.

Grayson, D. A. (1989). Twins reared together: Minimizing shared environmental effects. Behavior Genetics, 19, 593-604.

Johnson, A. M., Wadsworth, J., Elliott, P., Prior, L., Wallace, P., Blower, S., Webb, N. L., Heald, G. I., Miller, D. L., Adler, M. W., et al. (1989). A pilot study of sexual lifestyle in a random sample of the population of Great Britain. AIDS, 3, 135-141.

Jöreskog, K. G., \& Sörbom, D. (1993). PRELIS 2 [Computer software]. Chicago: Scientific Software.

Kasriel J., \& Eaves, L. J. (1976). A comparison of the accuracy of written questionnaires with blood-typing for diagnosing zygosity in twins. Journal of Biosocial Science, 8, 263-266.

Lord, F. M., \& Novick, M. R. (1968). Statistical theories of mental test scores. Reading, MA: Addison-Wesley.

Lyons, M. J., Faraone, S. V., Tsuang, M. T., Goldberg, J., Eaves, L. J., Meyer, J. M., True, W. R., \& Eisen, S. A. (1997). Another view on the "right" statistical measure of twin concordance. Archives of General Psychiatry, 54, 1126-1128.

Martin, N. G., \& Eysenck, H. J. (1976). Genetic factors in sexual behavior. In H. J. Eysenck (Ed.), Sex and personality. London: Open Books.

Martin, N. G., \& Martin, P. G. (1975). The inhertiance of scholastic abilities in a sample of twins: I. Ascertainment of the sample and diagnosis of zygosity. Annals of Human Genetics, 39, 213-218.

McGue, M., \& Lykken, D. T. (1992). Genetic influence on the risk of divorce. Psychological Science, 3, 368-373.

Mealey, L., Bridgstock, R., \& Townsend, G. C. (1999). Symmetry and perceived facial attractiveness: A monozygotic co-twin comparison. Journal of Personality and Social Psychology, 76, 151-158.

Mikach, S. M., \& Bailey, J. M. (1999). What distinguishes women with high numbers of sex partners. Evolution and Human Behavior, 20, $141-150$.

Moffitt, T. E., Caspi, A., Belsky, J., \& Silva, P. A. (1992). Childhood experience and the onset of menarche: A test of a sociobiological model. Child Development, 63, 47-58.

Molenaar, P. C., Boomsma, D. I., \& Dolan, C. V. (1993). A third source of developmental differences. Behavior Genetics, 23, 519-524.

Neale, M. C. (1995). MX: Statistical modeling (4th ed.). Richmond, VA: Department of Psychiatry, Virginia Commonwealth University.

Neale, M. C., \& Cardon, L. R. (1992). Methodology for genetic studies of twins and families. Dordrecht, the Netherlands: Kluwer Academic.

Neale, M. C., \& Eaves, L. J. (1993). Estimating and controlling for the effects of volunteer bias with pairs of relatives. Behavior Genetics, 23, 271-277.

Nunnally, J., \& Bernstein, I. (1994). Psychometric theory (3rd ed.). New York: McGraw-Hill.

Oliver, M. B., \& Hyde, J. S. (1993). Gender differences in sexuality: A meta-analysis. Psychological Bulletin, 114, 29-51.

Prescott, C. A., \& Gottesman, I. I. (1993, November). Power limitations in detecting heterogeneity of genetic effects: The case of sex differences in alcoholism. Paper presented at the meeting of the Society for Research on Psychopathology, Chicago.

Reich, T., Cloninger, C. R., \& Guze, S. B. (1975). The multifactorial model of disease transmission: I. Description of the model and its use in psychiatry. British Journal of Psychiatry, 127, 1-10.

Rice, W. R. (1999, June). Adaptation and coevolution of the sexes: Genderspecific fitness, interlocus contest evolution (ICE), and sexually antagonistic genes. Paper presented at the Annual Meeting of the Human Behavior and Evolution Society, Salt Lake City, UT.

Simpson, J. A., \& Gangestad, S. W. (1991). Individual differences in sociosexuality: Evidence for convergent and discriminant validity. Journal of Personality and Social Psychology, 60, 870-883.

Simpson, J. A., \& Gangestad, S. W. (1992). Sociosexuality and romantic partner choice. Journal of Personality, 60, 31-51.

Steinberg, L. (1988). Reciprocal relation between parent-child distance and pubertal maturation. Developmental Psychology, 24, 122-128.

Sundet, J. M., Magnus, P., Kvalem, I. L., Samuelsen, S. O., \& Bakketeig, L. S. (1992). Secular trends and sociodemographic regularities in coital debut age in Norway. Archives of Sexual Behavior, 21, 241-252.

Symons, D. T. (1979). The evolution of human sexuality. New York: Oxford University Press.

Trivers, R. L. (1972). Parental investment and sexual selection. In B. Campbell (Ed.), Sexual selection and the descent of man 1871-1971 (pp. 136-179). Chicago: Aldine-Atherton.

Waller, N. G., \& Shaver, P. (1994). The importance of nongenetic influences on romantic love styles: A twin-family study. Psychological Science, 5, 268-274.

Waynforth, D., Hurtado, A. M., \& Hill, K. (1998). Environmentally contingent reproductive strategies in Mayan and Ache males. Evolution \& Human Behavior, 19, 369-385.

Wilson, D. S. (1994). Adaptive genetic variation and human evolutionary psychology. Ethology \& Sociobiology, 15, 219-236.

Wright, R. (1994). The moral animal: Evolutionary psychology and everyday life. New York: Pantheon. 


\section{Appendix}

\section{Sociosexuality Scale Items and Endorsement Frequencies}

1. It is better not to have sex relations until you are married." (R)

$$
.18 \quad .23
$$

2. Virginity is a girl's most valuable possession. ${ }^{\text {a }}(\mathrm{R})$

$.32 \quad .32$

3. Sex without love (impersonal sex) is highly unsatisfactory. ${ }^{2}$ (R)

$.51 \quad .74$

4. I believe in taking my pleasures where I find them. ${ }^{a}$

$.43 \quad .25$

5. Absolute faithfulness to one's partner throughout life is nearly as silly as celibacy."
.13

.21

6. Sometimes sexual feelings overpower me. ${ }^{\mathrm{a}}$

7. Group sex appeals to me. ${ }^{\text {a }}$

$.24 \quad .04$

8. If I were invited to take part in an orgy, I would accept. ${ }^{a}$ $.28 \quad .03$

9. I can imagine myself being comfortable and enjoying "casual" sex with different partners. $.48 \quad .12$

10. I would have to be closely attached to someone (both emotionally and psychologically) before I could feel comfortable and fully enjoy having sex with him or her.
.52
.83

11. It would be difficult for me to enjoy having sex with someone I did not know very well. ${ }^{\text {a }}$ (R) $.48 \quad .83$

12. I could enjoy having sex with someone I was attracted to, even if I did not feel anything emotionally for him or her. ${ }^{\mathbf{a}}$

$$
.69 \quad .29
$$

13. The thought of an illicit sex affair excites me.

$$
.52 \quad .24
$$

14. Sex without love is ok. ${ }^{\mathrm{b}}$

$$
64 \quad .37
$$

15. The thought of a sex orgy is disgusting to me. ${ }^{\mathrm{a}}(\mathrm{R})$

$$
.30 \quad .66
$$

16. During your entire life, how many partners of the opposite sex have you had sexual contact with? ${ }^{\text {b }}$

17. With how many partners of the opposite sex have you had sexual intercourse within the past year?

18. With how many partners of the opposite sex do you foresee having sexual intercourse during the next five years? ${ }^{\mathrm{b}}$

19. With how many partners of the opposite sex have you had sexual intercourse on one and only one occasion? $^{\mathrm{b}}$

20. How often do you fantasize about having sex with someone other than your current dating partner/spouse? ${ }^{\mathrm{b}}$

Note. Endorsement frequencies represent the proportions of male and female participants, respectively, who responded "yes/agree" with the original wording of the question, and are provided after each dichotomouslyscored item. Items 16-20 were scored on a rating scale, and endorsement frequencies are not provided for them.

a From Sex and Personality, by H. J. Eysenck, 1976, Austin: University of Texas Press. Copyright 1976 by the University of Texas Press. Adapted with permission. ${ }^{b}$ Adapted from Simpson \& Gangestad (1991).

* Reverse scored. 